\title{
Annular electromagnetic stirring - a new method for the production of semi-solid A357 aluminum alloy slurry
}

\author{
Guanglei ZHU*, Jun XU, Zhifeng ZHANG, Yuelong BAI and Likai SHI
}

National Engineering \& Technology Research Center for Non-ferrous Metal Matrix Composites, General Research Institute for Non-ferrous Metals, Beijing 100088, China

Manuscript received 4 January 2009; in revised form 14 March 2009

\begin{abstract}
A new method for producing semisolid slurry, annular electromagnetic stirring (AEMS), to refine and spheroidize grains was exploited. Experimental work was undertaken to investigate the effects of cooling rate, stirring power and stirring time on the solidification behavior of A357 alloy using A-EMS. It was found that increasing the cooling rate and stirring power gave rise to substantial grain refinement, which could be attributed to the increase of effective nucleation rate caused by the extremely uniform temperature and composition fields in the bulk liquid during the initial stage of solidification. Results showed that a fully grain refined spherical structure could be obtained using proper processing conditions within $10 \mathrm{~s}$.
\end{abstract}

KEY WORDS Semisolid; Annular electromagnetic stirring; A357

\section{Introduction}

Semi-solid metal forming has been applied commercially on aluminum alloys for many years. Thixocasting and rheocasting are made up of two semisolid metal (SSM) processing routes used industrially. However, the semisolid microstructure is one of the keys to SSM processing. High-quality semisolid microstructure is present as fine and spherical particles, and with minimum entrapped liquid in the solid ${ }^{[1-3]}$. Different methods have been used extensively for this purpose, such as the electromagnetic stirring process (EMS) ${ }^{[4]}$, the new rheocasting $(\mathrm{NRC})$ process $^{[5]}$, the continuous rheoconversion process $(\mathrm{CRP})^{[6]}$, and the liquidus casting process ${ }^{[7]}$, etc. Among these methodsthe electromagnetic stirring has been recognized as the most efficient way to produce feedstock materials in industrial scale. However, inhomogeneous microstructure in radial direction of feedstock materials and the presence of primary phases with non globular morphologies are essential problems of EMS ${ }^{[8]}$. They can lead to an increase in high costs for reheating and partial remelting stage. Therefore, many researchers are still seeking new methods to replace EMS in order to decrease the production cost and simplify the process.

In the present paper, a new rheocasting process, annular electromagnetic stirring (AEMS), to refine and spheroidize grains was exploited. It can be used to produce semisolid slurries with thixotropic microstructures as feedstock materials and semisolid slurries for

\footnotetext{
${ }^{*}$ Corresponding author. PhD candidate; Tel.: +86 1082241229.

E-mail address: my2150@163.com (Guanglei ZHU)
}

DOI: $10.1016 / \mathrm{S} 1006-7191(08) 60116-7$ 
rheocasting. Compared with the ordinary electromagnetic stirring, A-EMS has some advantages as follows: lower cost, simple equipment, high productivity and high quality, etc. Therefore, A-EMS is alternative to the established EMS process that allows the production of semisolid slurry and feedstock materials.

\section{Experimental}

Commercial A357 alloy was used in this investigation because of its wider solid-liquid range and good fluidity. Its chemical composition (wt pct) was Si 7.63, Cu 0.1, Mg 0.54, Al bal. DTA result showed that liquidus temperature is $614{ }^{\circ} \mathrm{C}$. The experimental equipments are schematically shown in Fig.1. It is made of an electromagnetic stirring unit, an accurate temperature control unit and a stainless mould unit. The electromagnetic stirring zone, a cylindrical cavity with a size

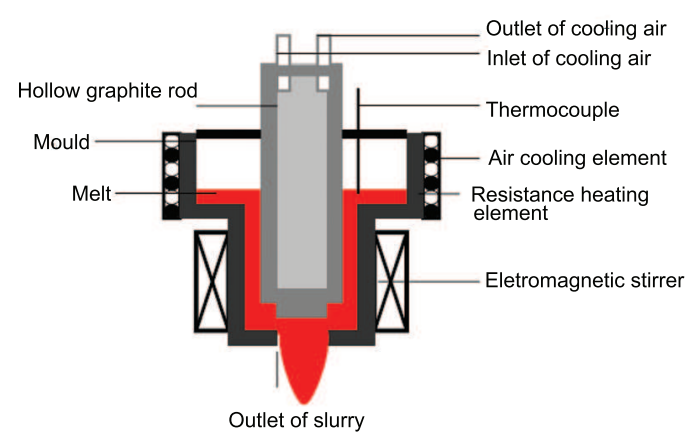

Fig.1 Schematic of annular electromagnetic stirring (A-EMS) process. of $80 \mathrm{~mm}$ diameter and $200 \mathrm{~mm}$ height, located at the bottom of the mould unit. The mould was preheated at a fixed temperature of $200{ }^{\circ} \mathrm{C}$ in a furnace. The aluminum alloy was melted at $710{ }^{\circ} \mathrm{C}$ in another electric resistance furnace and poured into the mould at $690{ }^{\circ} \mathrm{C}$. A thermocouple inserted was near the middle of the melt to record the temperature during the experiment. When the molten metal temperature decreased to $630{ }^{\circ} \mathrm{C}$, the stirring unit was actuated at a given stirring power and the hollow rod with cooling air was inserted. Since then the melt was cooled at a rate controlled by a cooling system. As soon as the temperature reached $600{ }^{\circ} \mathrm{C}$ or stirring time was up to a setting value, the outlet was opened. A slice of the alloy in the mould was sampled and quenched in water. All samples were prepared by a standard procedure, and etched in the $0.5 \% \mathrm{HF}$ acid. Microstructure examination was performed by a Zeiss optical microscope with a quantitative image analysis system. A close observation of microstructure could be given by average gain diameter $D=2(A / \pi)^{1 / 2}$ and shape factor $F=4 \pi A / P^{2}$, where $A$ and $P$ were average area and average perimeter of primary phase, respectively ${ }^{[9]}$.

\section{Results}

\subsection{Comparison between microstructures of A357 alloy produced by EMS and A-EMS}

Fig.2 shows the microstructures of specimens obtained with EMS and A-EMS at the same process conditions. It could be seen from Fig.2a that the primary phases of the specimen produced by EMS were rosette like. However, as it was shown in Fig.2b, applying A-EMS gave rise to the fine and equiaxed grains. Fig.3 shows the effects of rod size on average grain diameter and grain density of primary phases. It is effective to decrease average grain diameter and improve grain density of primary phases as the rod insertion size increases. The rod size of $40 \mathrm{~mm}$ was the biggest size in the experiment, an average grain diameter of $44 \mu \mathrm{m}$ was obtained. Compared with the microstructures obtained by the ordinary electromagnetic stirring, microstructures obtained by A-EMS were homogenous spherical and fine grains instead of dendritic and exhibited uniform distribution in the eutectic matrix. 


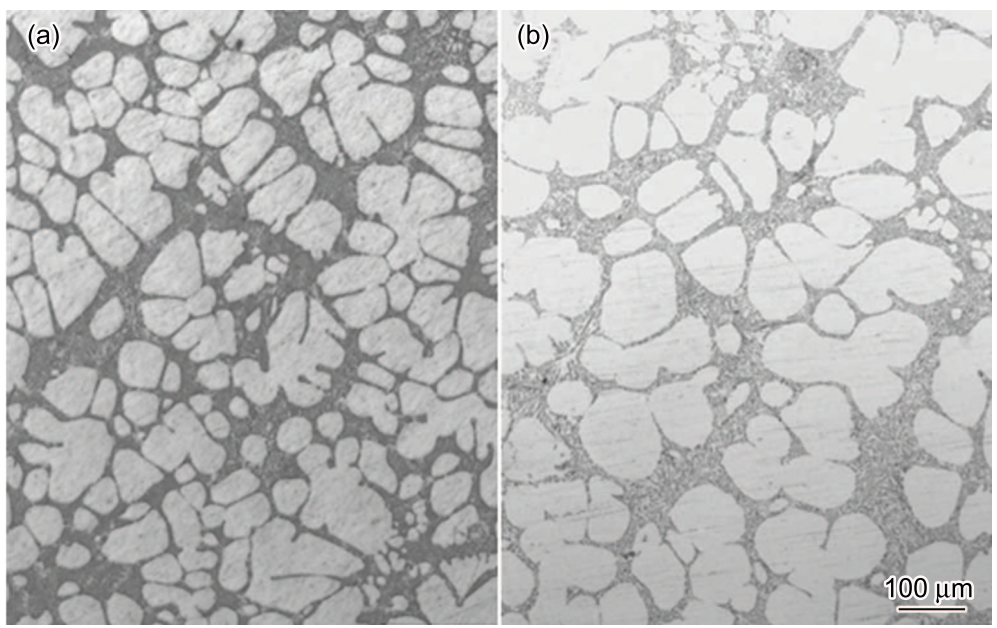

Fig.2 Morphology of primary phases in A357 alloy obtained at a melt temperature of $630{ }^{\circ} \mathrm{C}$, stirring power of $1.2 \mathrm{~kW}$ : (a) EMS (without rod insertion); (b) A-EMS (air flow of $0.1 \mathrm{~L} / \mathrm{min}$, rod size of $25 \mathrm{~mm}$ ).

\subsection{Microstructure evolution of A357}

alloy under stirring powers

Stirring power is a key process factor and has direct and positive influence on microstructure evolution. Fig.4 shows the semisolid microstructure of A357 alloy obtained by different stirring powers. Under stirring power of $0.4 \mathrm{~kW}$, dendritic phases were shown in Fig.4a. As stirring power increased to $0.8 \mathrm{~kW}$, primary phases displayed spherical and somewhat rosette-like particles, as shown in Fig.4b. Finally, primary phases were finer spherical particles at the stirring power of $1.2 \mathrm{~kW}$, as shown in Fig.4c.

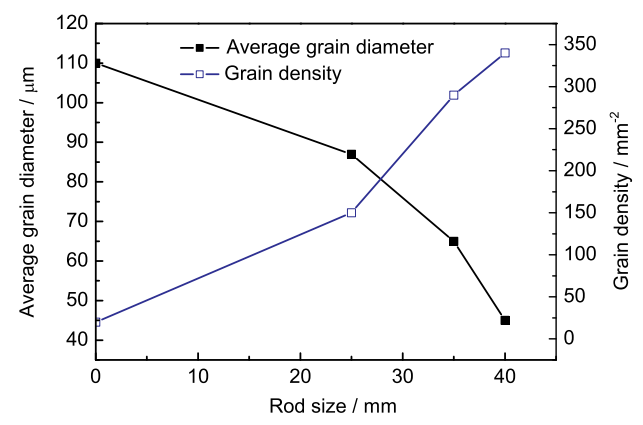

Fig.3 Effects of rod size on average grain diameter and grain density of primary phases.
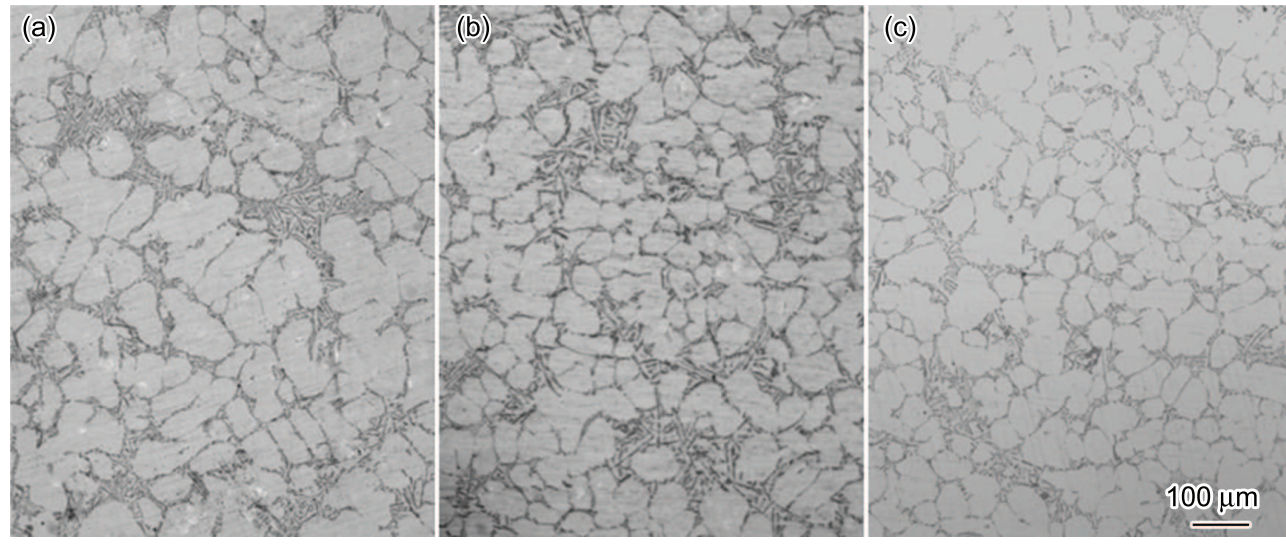

Fig.4 Morphology of primary phases in A357 alloy obtained at a melt temperature of $630{ }^{\circ} \mathrm{C}$, rod size of $40 \mathrm{~mm}$ and air flow of $0.1 \mathrm{~L} / \mathrm{min}$ : (a) $0.4 \mathrm{~kW}$; (b) $0.8 \mathrm{~kW}$; (c) $1.2 \mathrm{~kW}$. 
Fig.5 shows the effects of stirring power on average grain diameter and grain density of primary phases. It is evident that grain density increases and average grain diameter decreases with increasing stirring power.

\subsection{Microstructure evolution of A357}

alloy under different cooling rates

Fig. 6 shows the semisolid microstructure of A357 alloy obtained with cooling air and without cooling air. It could be seen from Fig.6a that a coarser microstructure was obtained without cooling air. However, primary phases became finer and more spherical as the cooling air flow increased as shown

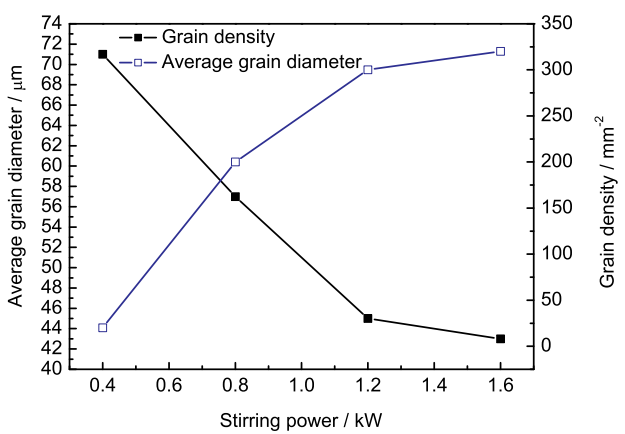

Fig.5 Effects of stirring power on average grain diameter and grain density of primary phases.

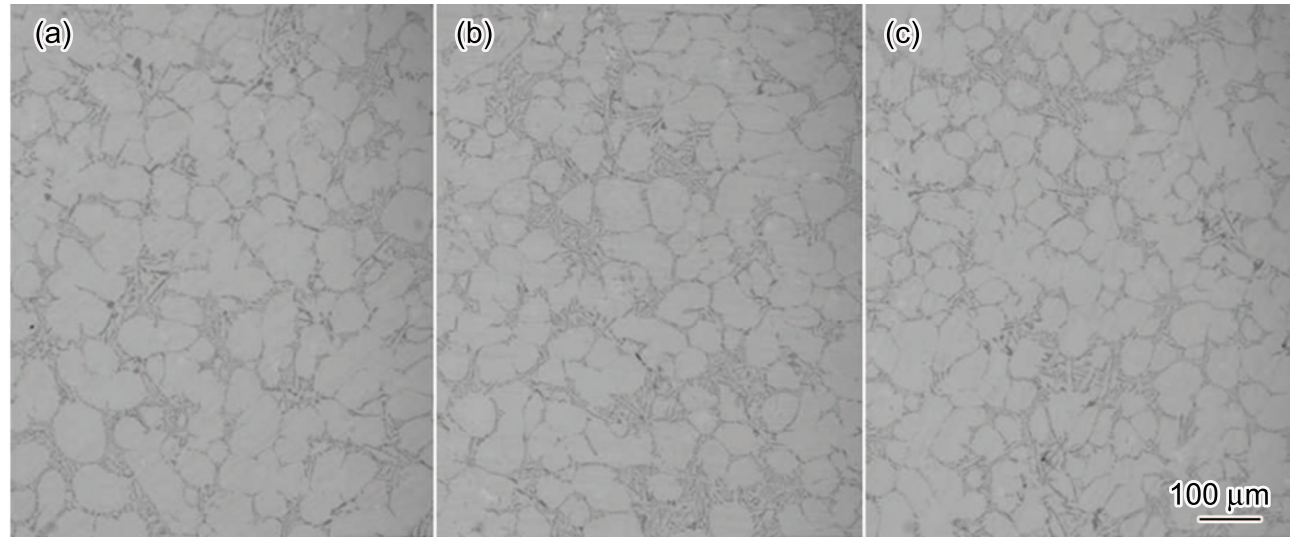

Fig.6 Morphologies of primary phases in A357 alloy obtained at a melt temperature of $630{ }^{\circ} \mathrm{C}$, stirring power of $1.2 \mathrm{~kW}$ and rod size of $40 \mathrm{~mm}$ with air flows $0 \mathrm{~L} / \mathrm{min}$ (a); $0.3 \mathrm{~L} / \mathrm{min}$ (b) and $0.5 \mathrm{~L} / \mathrm{min}(\mathrm{c})$.

in Fig.6b and 6c. As air flow was $0.3 \mathrm{~L} / \mathrm{min}$, the microstructure was mainly dominated by the fine spherical phases, the rosette primary phases disappeared. At the air flow of $0.5 \mathrm{~L} / \mathrm{min}$, the finer spheroidization of primary phases increased and separated from each other. The results described above suggest that increasing air flow leads to decrease average grain diameter and improve grain density of primary phases.

\subsection{Microstructure evolution of A357 alloy under different stirring times}

Stirring time is another key process factor on microstructure evolution. Fig.7 shows the semisolid microstructure of A357 alloy obtained under different stirring times. The morphology of primary phases still retained spherical between $2 \mathrm{~s}$ and $30 \mathrm{~s}$, but the distribution of average grain diameter and grain density of primary phases varied with stirring time. Fig. 8 shows the effects of stirring time on average grain diameter and grain density of primary phases. It is interesting to note that the critical value for the distribution of average grain diameter was same to grain density. That is, grain density increased continuously 


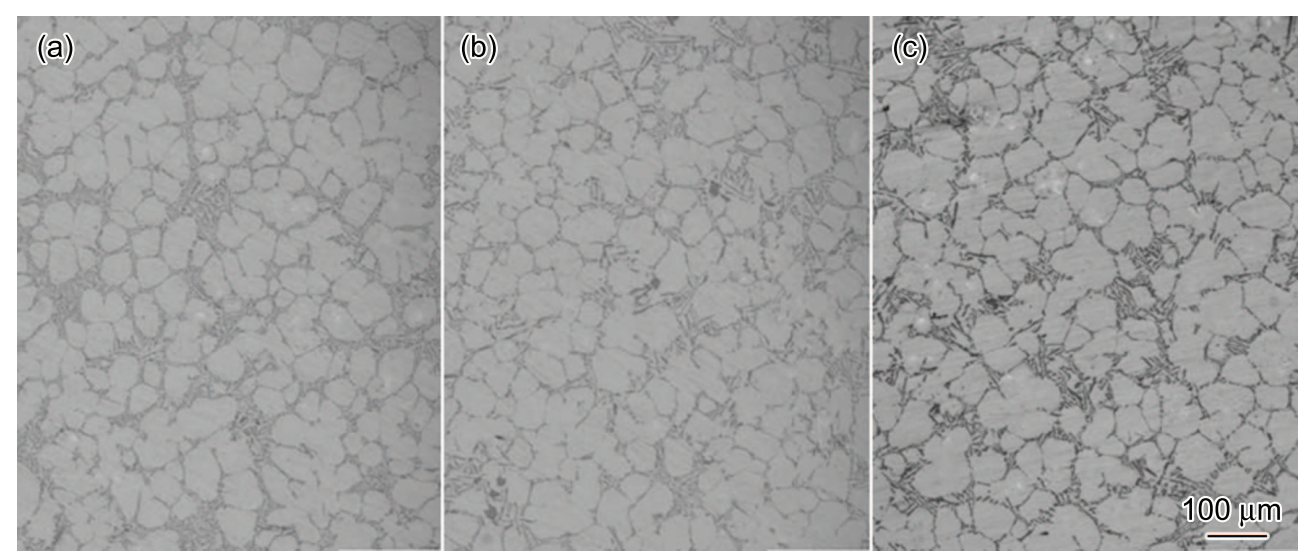

Fig.7 Morphologies of primary phases in A357 alloy obtained at a melt temperature of $630{ }^{\circ} \mathrm{C}$, stirring power of $1.2 \mathrm{~kW}$, rod size of $40 \mathrm{~mm}$ and air flow of $0.1 \mathrm{~L} / \mathrm{min}$ at $5 \mathrm{~s}(\mathrm{a}) ; 10 \mathrm{~s}(\mathrm{~b})$; $15 \mathrm{~s}(\mathrm{c})$.

and reached the peak at $10 \mathrm{~s}$. At the same time, average grain diameter also decreased gradually, reached the minimum value at $10 \mathrm{~s}$. Several experiments were performed between $2 \mathrm{~s}$ and $30 \mathrm{~s}$, it was confirmed that there was an ideal morphology of primary phases in the stirring time range of 5-20 s. The experimental results show that A-EMS process for producing semisolid slurry with thixotropic microstructure is efficient and practical in a short time.

\section{Discussion}

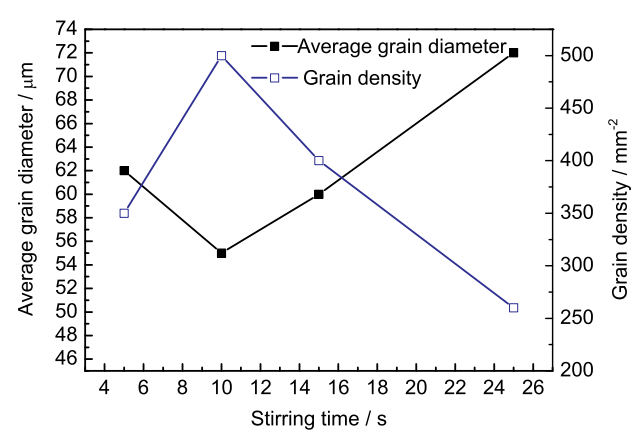

Fig.8 Effects of stirring time on average grain diameter and grain density of primary phases.

The core unit is the cooling rods in the experimental equipments, and almost every function of the equipments is related to the rod's functionality. When the rod is not inserted in the melt, A-EMS is similar to the ordinary electromagnetic stirring process. As the ordinary electromagnetic stirring has skin effect, shear rate at the edge of the melt is different from the center. Namely, shear rate is strong at the edge of the melt but weak in the center. Moreover, cooling rate is strong at the edge of the melt but weak in the center. As a result, the temperature field is not completely homogeneous in the melt, which can form a small grain density, the distances between the primary grains are large and diffusion fields overlap takes place at later times in solidification. Therefore, primary grains will have more chance and space for unstable growth, and dendritic microstructures or rosette microstructures can be obtained.

Conversely, the graphite rod with an air cooling can be attributed to the increase of effective nucleation rate caused by the extremely uniform temperature and composition fields in the bulk liquid during the initial stage of solidification. There are three chief reasons as follows: firstly, the hollow rod is cooled internally and externally by an air cooling system. Secondly,graphite is chosen because of its high thermal diffusivity and non-wetting behavior when exposed to the melt. The controlled cooling rate of the rod 
provides localized rapid cooling during the initial stage of solidification. The cooling rate of the rod is controlled by air flow. That is, cooling rate increases with increasing air flow. Subsequently, the cooling rate difference between the edge and the center is reduced because the radial distance of the melt decreases while the contact area increases. Finally, shear rate can be sharply increased on account of applying skin effect. Moreover, the larger diameter rod provides a larger shear rate and contact area in the melt. Therefore, the melt is cooled quickly to the temperature below its liquidus temperature because of a large and ever-renewing surface area between the melt and the wall, which is ideal for enhancing efficiency of heat extraction. As a result, the temperature field is extremely uniform and below its liquidus throughout the entire alloy melt, nucleation will occur in the entire volume of the liquid and each nucleus will survive. Many studies have already manifested that a high grain density is beneficial to the spherical growth of primary phases ${ }^{[10-13]}$. The probability of overlap of diffusion fields of the adjacent grains increases, which leads to the decrease of concentration gradient in front of solid-liquid interface and increase of their interface stability. In addition, the distribution of grains and spacing among them are uniform because of the forced stirring. Under this situation, the growth will be limited and stable, and ideal globular microstructures can be obtained.

During the continuous stirring stage of the primary solidification, grain density increased continuously and reached the peak at $10 \mathrm{~s}$. The increased grain density during the continuous cooling can be explained by a continuous nucleation mechanism. That is, all the nuclei could survive due to the uniform temperature and composition fields created by high cooling rate with stirring. This has been named as continuous effective nucleation ${ }^{[14,15]}$. However, low cooling rate in combination with stirring makes a small undercooling, which makes a continuous nucleation diminish. As a result, the cooling rate decreases on account of the increase of releasing latent heat of the alloy, a continuous nucleation is gradually decreased to disappear.

Grain density reached the peak at $10 \mathrm{~s}$, however, decreased gradually after then. Moreover, grain density decreased significantly with prolonged exposure to stirring time. The main reason for decreasing in primary solid grain density is coarsening effect, coarsening acts in opposite of grain refinement effect. As the starting grains are fairly spherical in shape, Ostwald ripening between different grains is the primary mechanism for reduction in surface energy. Primary phases with smaller sizes are dissolved in liquid as a result of increasing diffusion flux from interfaces with high roundness toward interfaces with low roundness ${ }^{[16]}$. As a result, the particle size increases and grain density decreases after $10 \mathrm{~s}$.

\section{Conclusions}

(1) Compared with the microstructures obtained by the ordinary electromagnetic stirring, the microstructures obtained by A-EMS were homogenous spherical and fine grains instead of dendritic and exhibited uniform distribution in the eutectic matrix.

(2) It was effective to decrease average grain diameter and improve grain density of primary phases by increasing rod diameter, air flow and stirring power, the finest and spherical grain with size of about $44 \mu \mathrm{m}$ were obtained in the experiment.

(3) During the continuous stirring stage of the primary solidification, grain density increased continuously, reached the peak at $10 \mathrm{~s}$. At the same time, average grain diameter 
also decreased gradually, reached the minimum value at $10 \mathrm{~s}$.

(4) There was an ideal morphology of primary phases in the stirring time range of 5-20 s. The experimental results show A-EMS process for producing semisolid slurry with thixotropic microstructure is efficient and practical in a short time.
Acknowledgements - The research was financially supported by National High Technical Research and De- velopment Program of China (No.2009AA03Z534) and National Basic Research Pro- gram of China (No.2006CB605203).

\section{REFERENCES}

[1] M.C. Flemings, Metall Trans 22A(5) (1991) 957.

[2] D.H. Kirkwood, Int Mater Rev 39 (1994) 173.

[3] Z. Fan, Int Mater Rev 47 (2002) 1.

[4] Z. Liu, W.M. Mao and Z.D. Zhao, Rare Met 26 (2006) 177.

[5] H. Kauhann, H.Wabusseg and P.J. Uggowitzer, Aluminum 76(1/2) (2000) 70.

[6] D. Apelian, Q.Y. Pan and M. Findon, Die Casting Engineer 48(1) (2004) 22.

[7] Y. Pan, S. Aoyama and C. Liu, Proc 5th Asian Foundry Congress, eds. G. Sun, H. Yuan, R. Yao and X. Yan (Southeast University Press, Nanjing, 1997) p.443.

[8] E. Tzimas and A. Zavaliangos, J Sci Eng A 289A (2000) 217.

[9] M. Suery, Proc of the 8th Int Conf on Semi-Solid Processing of Alloys and Composite (The Worcester Polytechnic Institute and the Metals Processing Institute, Limassol, Cyprus, 2004).

[10] R.A. Martinez and M.C. Flemings, Metall Mater Trans 36A(8) (2005) 2205.

[11] H.M. Guo, X.J. Yang and B. Hu, Solid State Phenomena 116-117 (2006) 425.

[12] T. Li, X. Lin and W.D. Huang, Acta Mater 54 (2006) 4815.

[13] A. Ohno, T. Motegi and H. Soda, Trans Iron Steel Inst Jpn 11 (1971) 18.

[14] Z. Fan and G. Liu, Sci Eng A 413-414 (2005) 229.

[15] S. Ji, Z. Fan and M.J. Bevis, Mater Sci Eng A 299(1-2) (2001) 210.

[16] H.V. Atkinson and D.Liu, Mater Sci Eng A 496 (2008) 439. 